\title{
Pengaruh Kemampuan Akademik Micro Teaching Terhadap Kemampuan Real Teaching Mahasiswa Program Studi Pendidikan Ekonomi Angkatan 2014
}

\author{
Fransiskus Korosando, Maria Anita Bada
}

e-mail: atatomberabu@gmail.com

Program Studi Pendidikan Ekonomi, FKIP, Universitas Flores

\begin{abstract}
ABSTRAK: Kegiatan pembelajaran mikro (micro teaching) di Program Studi Pendidikan Ekonomi merupakan proses transformasi ilmu pengetahuan membentuk karakter mahasiswa calon guru yang memiliki keterampilan-keterampilan mengajar yang spesifik sebelum melaksanakan program real teaching. Secara pragmatis ditemukan penguasaan materi yang kurang komprehensif, penguasaan kelas kurang maksimal, kecanggungan serta canggung menjadi modus dalam pembelajaran micro teaching. Selain itu juga dipengaruhi keterbatasan frekwensi bermicro teaching. Perolehan nilai dengan predikat baik/sangat baik dalam kegiatan micro teaching belum dapat dijadikan sebagai andil untuk mengatakan bahwa seorang mahasiswa Program Studi Pendidikan Ekonomi Angkatan 2014 akan mampu melaksanakan program real teaching dengan baik.
\end{abstract}

Kata kunci : kemampuan akademik micro teaching, kemampuan real teaching.

ABSTRACT: Micro learning activities (micro teaching) in the Economic Education Study Program is a process of transforming science to shape the character of prospective teacher students who have specific teaching skills before implementing a real teaching program. Pragmatically, mastery of the material is less comprehensive, mastery of classes is less than optimal, awkwardness and awkwardness become modes of learning in micro teaching. It is also influenced by the limitation of the frequency of teaching micro. The acquisition of good / excellent grades in micro teaching activities cannot be used as a contribution to say that a 2014 Class of Economics Education Study Program student will be able to carry out real teaching programs well.

Keywords: micro teaching academic ability, real teaching ability.

\section{PENDAHULUAN}

Penyelenggaraan pendidikan di Universitas Flores diarahkan untuk mewujudkan cita-cita bangsa yang termaktub dalam alinea keempat UndangUndang Dasar Negara Republik Indonesia 1945 serta mewujudkan visi mediator budaya dalam bingkai semangat satukan langkah, bulatkan tekad menuju Universitas Flores bermutu.

Implementasi arah dan perwujudan di atas diaktualisasikan dalam multi aspek, salah satunya adalah aspek pembelajaran yang dilaksanakan sesuai karakteristik keilmuan pada setiap fakultas maupun program studi. Dengan demikian dapat dikatakan bahwa pembelajaran yang dilakukan di Program Studi Pendidikan Ekonomi adalah proses transformasi ilmu pengetahuan yang relevan guna mempersiapkan dan membentuk karakter mahasiswa calon guru yang memiliki kompetensi yang kemudian akan mencerdaskan generasi muda bangsa dan sebagai mediator budaya di tengah lingkungan kerja maupun masyarakat.

Secara teoretis, mahasiswa diwajibkan untuk memiliki penguasaan teoretis berkaitan dengan ilmu pendidikan 
dan ilmu keguruan serta ilmu ekonomi untuk diaktulisasasikan dalam kegiatan pembelajaran mikro (micro teaching) maupun pada situasi yang sesungguhnya pada program pengalaman lapangan/PPL (real teaching). Micro teaching merupakan bentuk pengajaran yang sederhana, didesain bagi mahasiswa calon guru belajar mengajar dalam suasana kelas yang terbatas dan terkontrol untuk mempraktekkan keterampilanketerampilan mengajar yang spesifik sebelum melaksanakan pembelajaran di sekolah praktik dalam program real teaching. Mc. Laughlin \& Moulton (Asril, 2012: 43;56) mengemukakan: Micro teaching is as performance training method desingned to isolate the compenent part of teaching process, so that the trainee can master each component one by in simplified teaching situasion. dikemukakan pula bahwa micro teaching bukan pengganti praktik lapangan melainkan bagian dari program pengalaman lapangan yang berusaha untuk menimbulkan, mengembangkan serta membina keterampilan-keterampilan tertentu dari calon-calon guru dalam menghadapi kelas.

Secara pragmatis ditemukan penguasaan materi yang kurang komprehensif, penguasaan kelas kurang maksimal, kecanggungan serta canggung menjadi modus dalam pembelajaran micro teaching. Hal ini dapat dimaklumi karena menjadi pemula dan sedang belajar mencari bentuk pendidik yang ideal. Selain itu juga dipengaruhi oleh kesiapan mahasiswa beradaptasi dengan situasi micro teaching dan keterbatasan frekwensi bermicro teaching sebanyak dua kali praktik untuk setiap mahasiswa. Temuan di atas dipadang belum mumpuni sebagai andil bagi mahasiswa Program Studi Pendidikan Ekonomi Angkatan 2014 dalam mengikuti program real teaching, atau dengan kata lain kemampuan akademik yang ditandai dengan perolehan nilai dengan predikat baik/sangat baik dalam kegiatan micro teaching belum dapat dijadikan sebagai dasar mutlak untuk mengatakan bahwa seorang mahasiswa Program Studi Pendidikan Ekonomi Angkatan 2014 akan mampu melaksanakan program real teaching dengan baik.

\section{LANDASAN TEORI}

\section{Micro Teaching}

a. Pengertian

Menurut Mc. Laughlin \& Moulton mengemukakan: Micro teaching is as performance training method desingned to isolate the compenent part of teaching process, so that the trainee can master each component one by in simplified teaching situasion. (Asril, 2012:43).

Pembelajaran mikro (micro teaching) adalah salah satu pendekatan atau cara untuk melatih penampilan mengajar yang dilakukan secara "micro" atau disederhanakan (Sukirman, 2012:21).

Pelaksanaan pembelajaran microteaching yang dilaksanakan pada Program Studi Pendidikan Ekonomi dilaksanakan dengan mengintegrasikan program lesson study yang dikonsepkan oleh Susilo (2011:35) meliputi 3 tahap: tahap Perencanaan (Plan), tahap pelaksanaan $(D o)$, tahap pengamatan dan refleksi (See).

b. Tujuan

Dwight Allen dalam Asril (2012:46), mengemukakan tujuan micro teaching bagi guru; (1) Memberikan penyegaran dalam program pendidikan. (2) guru mendapatkan pengalaman mengajar yang bersifat individual demi perkembangan perofesinya.

Mengembangkan sikap terbuka bagi guru terhadap pembaharuan yang berlangsung di pranata pendidikan.

c. Manfaat

Menurut Asril (2012), dengan membekali mahasiswa melalui 
pengajaran mikro, maka ada beberapa manfaat yang diperoleh, yakni: (1) Mengembangkan keterampilanketerampilan tertentu calon guru dalam mengajar. (2) Keterampilan mengajar yang esensial secara terkontrol dapat dilatihkan. (3) Balikan (feed-back) yang tepat dapat segera diperoleh. (4) Latihan memungkinkan penguasaan komponen keterampilan mengajar secara lebih baik. (5) Dalam situasi latihan, calon guru atau guru dapat memusatkan perhatian secara khusus. (6) Menuntut dikembangkannya pola observasi yang sistematis dan objektif. (7) Mempertinggi efisiensi dan efektifitas penggunaan sekolah praktek dalam waktu praktek mengajar yang relatif singkat.

\section{Praktik Pengalaman Lapangan}

a. Pengertian

Permendiknas No. 16 Tahun 2007, mengamanatkan bahwa PPL merupakan ajang untuk membentuk dan membina kompetensi yang dipersyaratkan oleh profesi pendidik. Sasaran yang ingin dicapai adalah pribadi calon guru yang memiliki seperangkat pengetahuan, keterampilan, nilai dan sikap, serta pola tingkah laku yang diperlukan bagi profesinya serta cakap dan tepat menggunakannya di dalam penyelenggaraan pendidikan dan pengajaran di sekolah maupun di luar sekolah.

Secara institusional Program studi Pendidikan Ekonomi FKIP Universitas Flores memiliki strategi (integrasi teori dan praktik) untuk mendidik mahasiswa menjadi calon guru yang profesional. Secara pragmatis, mahasiswa diwajibkan menempuh mata kuliah pendidikan dan keguruan (mata kuliah prasyarat) sebelum memrogramkan mata kuliah praktik seperti micro teaching dan praktik pengalaman lapangan. Hal ini senada dengan pandangan Karwono dan Mularsih (2012:3) bahwa pembentukan kemampuan profesionalisme keguruan memerlukan pengintegrasian fungsional antara teori, praktik dan materi serta metodologi penyampaianya. Oleh karena itu PPL merupakan ajang aktualisasi kemampuan diri untuk mentransformasikan ilmu pengetahuan pendidikan dan keguruan yang diperolehnya sekaligus investasi pengalaman dalam rangka membentuk kompetensi pedagogis dan profesionalitas diantaranya; menyusun rencana pembelajaran, penggunaan alat/media pembelajaran, penguasaan materi pembelajaran, penguasaan dinamika kelas, dan penilaian.

Fitria Novitasari, dkk (2013) mengemukakan, kesiapan mahasiswa untuk menjadi seorang tenaga pendidik dapat diukur berdasarkan tingkat kualitas penguasaan empat kompetensi mengajar yakni kompetensi pedagogik, kompetensi kepribadian, kompetensi sosial dan kompetensi profesional. Keempat kompetensi tersebut bersifat saling melengkapi satu sama lain. Melalui kegiatan PPL mahasiswa diharapkan dapat menguasai empat kompetensi mengajar secara selaras serta dapat mengintergrasikan keempat kompetensi mengajar tersebut dalam diri mahasiswa dengan baik.

b. Tujuan

Menurut Asril (2012)
terdapat 6 tujuan umum program
pengalaman lapangan 3 diantaranya
adalah: (1) Membimbing para calon
guru agar kepribadiannya dalam
pendidikan atau sebagian guru yang
baik dan setia pada profesinya,
menguasai dan mampu
mengembangkan ilmu-ilmu sesuai
dengan bidang pendidikan dan


perkembangan zaman serta cakap menyelenggarakan pendidikan di sekolah maupun diluar sekolah. (2) Melatih dan meningkatkan kompetensi keguruan mahasiswa agar dapat terampil melaksanakan tugas-tugas kependidikan baik yang bersifat edukatif, administratif maupun layanan bimbingan keagamaan dan kesiswaan. Memberikan pengalaman kepada mahasiswa untuk dapat memahami keberadaan lembaga pendidikan dengan segala permasalahannya baik yang berhubungan dengan proses pembelajaran maupun pengelolaan sekolah secara umum. Selain itu terdapat tujuan khusus dari program pengalaman lapangan itu adalah agar seorang calon guru dapat menyumbangkan dan mengembangkan ilmunya sesuai dengan profesi yang dimilikinya.

\section{METODE}

Jenis penelitian yang digunakan adalah penelitian korelasi yakni korelasi kemampuan akademik micro teaching terhadap kemampuan real teaching. Penelitian ini dilakukan pada mahasiswa
Program Studi Pendidikan Ekonomi Fakultas Keguruan dan Ilmu Pendidikan Universitas Flores angkatan 2014 sebanyak 64 orang, yang telah memrogramkan mata kuliah micro teaching, dan real teaching. Data dikumpulkan dengan teknik dokumentasi, berupa hasil penilaian dari kedua mata. Uji prasyarat dalam penelitian ini adalah uji normalitas dan uji linearitas. Selanjutnya untuk mengetahui hubungan kedua variabel diuji dengan menggunakan analisis regresi dengan bantuan SPSS v.16.00 .

\section{PEMBAHASAN}

\section{Uji Normalitas}

Uji normalitas menggunakan bantuan program SPPS v.16.00 dengan tujuan untuk mengetahui apakah data terdistribusi secara normal atau tidak. Uji normalitas menggunakan metode uji Kolmogorov-Smirnov Test (K-S). Syarat normalitas akan terpenuhi jika nilai pengujian atau probabilitas lebih besar dari signifikansi hitung 0,05 ( $p>0,05)$. Sebelum ditampilkan tabel normalitas data terlebih dahulu ditampilkan tabel deskripsi statistik.

Tabel 1.

Descriptive Statistics

\begin{tabular}{|c|r|r|r|r|r|}
\hline & \multicolumn{1}{|c|}{$N$} & Mean & Std. Deviation & Minimum & Maximum \\
\hline micro & 64 & 3.0156 & .80656 & .00 & 4.00 \\
real & 64 & 2.9844 & 1.14770 & .00 & 4.00 \\
\hline
\end{tabular}

Data hasil analisis pada tabel tersebut di atas menunjukan rata-rata kemampuan akademik micro teaching sebesar 3.0156 dan 2.9844 kemampuan real teaching atau memperoleh nilai tertinggi 4 dan terendah 0 pada 64 mahasiswa Pendidikan Ekonomi. 
Tabel 2.

Uji Normalitas Tahap I

One-Sample Kolmogorov-Smirnov Test

\begin{tabular}{|ll|r|r|}
\hline & & micro & \multicolumn{1}{|c|}{ real } \\
\hline$N$ & & 64 & 64 \\
Normal Parameters $^{a}$ & Mean & 3.0156 & 2.9844 \\
& Std. Deviation & .80656 & 1.14770 \\
Most Ex 34.treme & Absolute & .320 & .396 \\
Differences & Positive & .258 & .188 \\
& Negative & -.320 & -.396 \\
Kolmogorov-Smirnov $Z$ & & 2.563 & 3.168 \\
Asymp. Sig. (2-tailed) & & .000 & .000 \\
\hline a. Test distribution is Normal. & & \\
\hline
\end{tabular}

Nilai Asymp. Sig.(2-tailed) di atas menunjukan lebih rendah dari 0,05 yakni 0,000 pada kedua variabel menunjukan syarat normalitas data tidak terpenuhi. Untuk maksud normalitas data dilakukan pengujian lanjutan beberapa kali untuk pendeteksian outlier yang mengandung extreme value (highest case number) hingga memenuhi syarat normalitas data yakni $\mathrm{p}>0,05$.

Tabel 3.

Tabel Uji Normalitas Pasca Pendeteksian Outlier One-Sample Kolmogorov-Smirnov Test

\begin{tabular}{|ll|r|r|}
\hline & & micro & \multicolumn{1}{|c|}{ real } \\
\hline$N$ & & 13 & 13 \\
Normal Parameters $^{a}$ & Mean & 2.9231 & 1.6154 \\
& Std. Deviation. & 1.32045 & 1.55662 \\
Most Extreme Differences & Absolute & .254 & .352 \\
& Positive & .207 & .312 \\
& Negative & -.254 & -.352 \\
& .916 & 1.268 \\
Kolmogorov-Smirnov Z & & .370 & .080 \\
Asymp. Sig. (2-tailed) & & & \\
\hline a. Test distribution is Normal. & &
\end{tabular}

Hasil analisis menunjukkan 13 data yang berdistribusi normal dengan ratarata 2,9231 untuk variabel micro teaching, 1,6154 untuk variabel real teaching. Sedangkan simpangan baku pada kedua variabel terpaut 0,23617 . Hasil uji normalitas data pada kedua variabel ditunjukkan dengan asymp. Sig. (2-tailed) lebih tinggi dari 0,05. 


\section{Uji Regresi Linear Sederhana}

Analisis regresi dimaksudkan untuk memprediksi pengaruh, dan linearitas dari variabel kemampuan akademik micro teaching terhadap kemampuan real teaching. Hasil analisis regresi dipaparkan berikut ini.

Tabel 5.

Model Summary ${ }^{b}$

\begin{tabular}{|l|r|r|r|r|}
\hline Model & \multicolumn{1}{|c|}{$R$} & $R$ Square & Adjusted $R$ Square & Std. Error of the Estimate \\
\hline 1 & $.795^{\mathrm{a}}$ & .632 & .599 & .98569 \\
\hline
\end{tabular}

a. Predictors: (Constant), micro

b. Dependent Variabel: real

Tabel model summary ${ }^{b} \mathrm{di}$ atas menunjukkan koefisien determinasi $(R$ Square) sebesar 0.632 yang menggambarkan pengaruh variabel kemampuan akademik micro teaching sebesar 63.2\% lebih dominan dari variabel lainnya sebesar $36.8 \%$.

Tabel 6.

Coefficients $^{a}$

\begin{tabular}{|rr|r|r|r|r|r|}
\hline \multirow{2}{*}{ Model } & \multicolumn{2}{|c|}{ Unstandardized Coefficients } & $\begin{array}{c}\text { Standardized } \\
\text { Coefficients }\end{array}$ & & \\
\cline { 2 - 5 } & \multicolumn{1}{|c|}{$B$} & Std. Error & \multicolumn{1}{c|}{ Beta } & \multicolumn{1}{c|}{ Sig. } \\
\hline 1 & (Constant) & -1.125 & .687 & & -1.638 & .130 \\
& Micro & .938 & .215 & .795 & 4.351 & .001 \\
\hline
\end{tabular}

a. Dependent Variabel: real

Output hasil analisis pada tabel coefficients $^{a}$ di atas menunjukkan: Pertama. Konstanta (a) sebesar -1.125; artinya jika kemampuan akademik micro teaching nilainya 0 , maka kemampuan real teachingnya nilainya sebesar-1,12. Kedua, Nilai B pada unstandardized coefficients menggambarkan kemampuan akademik micro teaching (b) sebesar 0.938 sehingga persamaan regresinya regresi $P=a+b x \quad P=-1.125+0.938 x$. Ketiga, Koefisien b menunjukkan arah regresi positif atau menanjak yang ditandai dengan nilai $b=0.938$ bertanda positif. Hal ini berarti setiap bertambahnya satu kemampauan akademik micro teaching maka mean kemampuan real teaching bertambah sebesar 0.938. Jika variabel kemampuan akademik micro teaching diketahui (nilai 3) maka kemampuan real teaching dapat diestmasi dengan cara memasukan nilai tersebut dalam persamaan.

$$
\begin{aligned}
Y & =-1.125+0.938 x \\
& =-1.125+0.938(3) \\
& =-1.125+2.814 \\
& =1.689
\end{aligned}
$$

Jadi nilai kemampuan real teachingnya diestimasi sebesar 1.689 
Tabel 7.

ANOVA ${ }^{b}$

\begin{tabular}{|c|c|c|c|c|c|c|}
\hline \multicolumn{2}{|c|}{ Model } & Sum of Squares & $D f$ & Mean Square & $F$ & Sig. \\
\hline 1 & Regression & 18.389 & 1 & 18.389 & 18.927 & $.001^{\mathrm{a}}$ \\
\hline & Residual & 10.688 & 11 & .972 & & \\
\hline & Total & 29.077 & 12 & & & \\
\hline
\end{tabular}

a. Predictors: (Constant), micro

b. Dependent Variabel: real

Variasi kemampuan akademik ditunjukkan dengan besarnya nilai $\mathrm{F}$ hitung $=18.927, \quad$ sedangkan signifikansinya 0.001 lebih kecil dari 0.05. Dengan demikian dapat

\section{Uji Signifikansi (Uji t)}

Uji ini digunakan untuk mengetahui signifikansi variabel kemampuan akademik micro teaching terhadap variabel kemampuan real teaching. Signifikan berarti pengaruh yang terjadi dapat digeneralisasikan pada populasi.

Nilai $\mathrm{t}$ pada tabel di atas diketahui sebesar 4.351 dengan signifikansi

disimpulkan H0 ditolak, atau dengan kata lain variasi kemampuan akademik micro teaching dapat menjelaskan variasi kemampuan real teaching.

sebesar 0.001 lebih kecil dari 0.05 (sig $<$ 0.05) menunjukkan H0 ditolak, artinya ada korelasi dan signifikan antara variabel kemampuan akademik micro teaching terhadap kemampuan real teaching.

\section{Uji Linearitas}

Hasil uji linearitas ditunjukkan dalam tabel Anova berikut ini.

Tabel 8 .

ANOVA Table

\begin{tabular}{|c|c|c|c|c|c|c|c|}
\hline & & & $\begin{array}{l}\text { Sum of } \\
\text { Squares }\end{array}$ & $d f$ & $\begin{array}{l}\text { Mean } \\
\text { Square }\end{array}$ & $F$ & Sig. \\
\hline \multirow{5}{*}{$\begin{array}{l}\text { Real teaching } \\
* \text { Micro } \\
\text { Teaching }\end{array}$} & Between & (Combined) & .458 & 3 & .153 & .646 & .589 \\
\hline & Groups & Linearity & .026 & 1 & .026 & .111 & .741 \\
\hline & & $\begin{array}{l}\text { Deviation } \\
\text { from } \\
\text { Linearity }\end{array}$ & .432 & 2 & .216 & .914 & .407 \\
\hline & \multicolumn{2}{|c|}{ Within Groups } & 12.525 & 53 & .236 & & \\
\hline & \multicolumn{2}{|l|}{ Total } & 12.982 & 56 & & & \\
\hline
\end{tabular}

Nilai signifikansi pada linearity pada tabel di atas sebesar 0.741 lebih kecil

\section{KESIMPULAN}

Berdasarkan hasil analisis dan pembahasan dapat disimpulkan: dari 0.05. artinya kedua variabel tersebut berpola tidak linear. 
ditunjukkan dengan konstanta (a) sebesar -1.125. Dengan demikian jika kemampuan micro teaching di tingkat sebesar satu, maka akan meningkatkan kemampuan real teaching sebesar 0,938, yang ditunjukkan dengan koefisien regresi 0,938 .

Koefisien regresi menunjukkan hubungan positif antara kedua variabel. Persamaan regresi $\quad P=$ $a+b x \quad P=-1.125+0.938 x$

2. Variasi kemampuan akademik ditunjukkan dengan besarnya nilai $\mathrm{F}$ hitung $=18.927$.

3. Nilai $t$ sebesar 4.351 dengan signifikansi sebesar 0.001 lebih kecil dari 0.05 (sig < 0.05) menunjukkan variasi kemampuan akademik micro teaching dapat menjelaskan variasi kemampuan real teaching. Dengan demikian dinyatakan $\mathrm{H}_{0}$ ditolak, artinya ada korelasi dan signifikan antara variabel kemampuan akademik micro teaching dengan kemampuan real teaching.

4. Nilai signifikansi pada linearity diketahui 0.741 lebih kecil dari 0.05 . menunjukan kedua variabel tersebut berpola tidak linear.
Sukirman, Dadang. 2012. Pembelajaran Micro Teaching. Jakarta:Direktorat Jendral Pendidikan Islam Kementerian Agama.

Susilo, H, Chotimah, H, Joharmawan, R,Jumiati, Dwita sari, Y, dan Sunarjo. 2011. Lesson Study Berbasis Sekolah. Malang: Bayumedia Publising.

\section{Daftar Pustaka}

Asril Zaenal. (2012). Micro Teaching :

Jakarta, Grasindo Persada.

Hartono. (2008). SPSS 16.0 Analisis Data

Statistika dan Penelitian:

Yogyakarta. Pustaka Pelajar.

MaPan (2015). Jurnal Matematika dan

Pembelajaran p-ISSN: 2354-

6883; e-ISSN: 2581-172X

Volume 3, Nomor 1, Juni 2015.

Santoso Singgih, (2005). Menggunakan

SPSS Untuk Statistik Parametrik:

Jakarta, Gramedia, 